\title{
A Comprehensive Study on Simulation Techniques for 5G Networks: State of the Art Results, Analysis, and Future Challenges
}

\author{
Panagiotis K. Gkonis ${ }^{1, *(D)}$, Panagiotis T. Trakadas ${ }^{1}$ and Dimitra I. Kaklamani ${ }^{2}$ \\ 1 General Department, National and Kapodistrian University of Athens, Sterea Ellada, \\ 34400 Dirfies Messapies, Greece; ptrakadas@uoa.gr \\ 2 Intelligent Communications and Broadband Networks Laboratory, School of Electrical and Computer \\ Engineering, National Technical University of Athens, 9 Heroon Polytechneiou str, Zografou, \\ 15780 Athens, Greece; dkaklam@mail.ntua.gr \\ * Correspondence: pgkonis@uoa.gr
}

Received: 27 February 2020; Accepted: 10 March 2020; Published: 11 March 2020

\begin{abstract}
In this review article, a comprehensive study is provided regarding the latest achievements in simulation techniques and platforms for fifth generation (5G) wireless cellular networks. In this context, the calculation of a set of diverse performance metrics, such as achievable throughput in uplink and downlink, the mean Bit Error Rate, the number of active users, outage probability, the handover rate, delay, latency, etc., can be a computationally demanding task due to the various parameters that should be incorporated in system and link level simulations. For example, potential solutions for 5G interfaces include, among others, millimeter Wave (mmWave) transmission, massive multiple input multiple output (MIMO) architectures and non-orthogonal multiple access (NOMA). Therefore, a more accurate and realistic representation of channel coefficients and overall interference is required compared to other cellular interfaces. In addition, the increased number of highly directional beams will unavoidably lead to increased signaling burden and handovers. Moreover, until a full transition to $5 \mathrm{G}$ networks takes place, coexistence with currently deployed fourth generation (4G) networks will be a challenging issue for radio network planning. Finally, the potential exploitation of $5 \mathrm{G}$ infrastructures in future electrical smart grids in order to support high bandwidth and zero latency applications (e.g., semi or full autonomous driving) dictates the need for the development of simulation environments able to incorporate the various and diverse aspects of $5 \mathrm{G}$ wireless cellular networks.
\end{abstract}

Keywords: 5G; mmWave transmission; massive MIMO systems; system level simulators; link level simulators; radio network planning

\section{Introduction}

The deployment of wireless cellular networks back in the early 1980s made feasible communications via portable devices, thus decoupling call establishment from existing location. In the next decades, technological achievements such as data exchange, which was introduced in second generation $(2 \mathrm{G})$ wireless cellular networks, or multimedia communications, which was a key concept of third generation (3G) networks, enabled the delivery of even higher data rates to mobile users (MUs) and a more efficient spectrum utilization compared to second generation systems [1]. In March 2009, the International Telecommunications Union-Radio communications sector (ITU-R) specified a list of requirements for fourth generation (4G) systems, named the International Mobile Telecommunications Advanced (IMT-Advanced) specification, setting peak speed requirements for $4 \mathrm{G}$ services at $100 \mathrm{Mbs}$ for high mobility communications (such as from trains and cars) and $1 \mathrm{Gbs}$ for low mobility communications (such as pedestrians and stationary users) [2]. 
The era of $3 \mathrm{G}$ and $4 \mathrm{G}$ networks coincided with scientific progress in other related fields, such as micro and power electronics, as well as hardware minimization and related improvements. This in turn made feasible the development of advanced transceiver architectures able to support among others large bandwidth operations and multiple Radio Frequency (RF) chains. Therefore, a quite popular transmission technique that has been studied thoroughly over the previous two decades is the use of antenna arrays at both ends of a wireless orientation, also known as multiple input multiple output (MIMO). Research on MIMO systems was mainly boosted after the pioneering work of Alamouti [3]. As shown in [4-6], MIMO systems can provide, among other benefits, diversity and spatial multiplexing gain. In the first case, the same symbol information is sent and received over multiple antennas; hence, the mean Bit Error Rate (BER) is reduced, due to the presence of multiple diversity branches. In the spatial multiplexing mode, individual data streams are sent from different transmit antennas. Therefore, overall network throughput can be improved, at the cost, however, of increased hardware complexity, as the diversity order of the orientation is reduced.

Although MIMO systems were incorporated in $3 \mathrm{G}$ and $4 \mathrm{G}$ standards $[7,8]$, the increasing demand for even higher data rates as well as traffic congestion (i.e., total requested throughput per area) led the scientific community to seek additional bandwidth efficient solutions [9]. Observing the evolution of generations of mobile communication systems, one easily realizes that there is an endless quest for an equilibrium between serving the exponentially increasing user needs (global wireless traffic volume in 2013 increased 30 times compared to that in 2008 [10]), and developing innovative technologies to enhance operational capabilities and network capacity given the scarce spectrum (wireless communications capacity in 2008 has increased by one million times compared to 1957 [11]). In this context, various solutions have been proposed for the deployment of 5G networks, such as mmWave transmission [12-14], massive MIMO systems [15-17], non-orthogonal multiple access (NOMA) schemes [18-21] as well as flexible network deployment along with nomadic nodes [22,23] (e.g., drones, uav, etc.). In the first case, mmWave spectrum covers the range from $30 \mathrm{GHz}$ to 300 $\mathrm{GHz}$ (with equivalent wavelengths from 10 to $1 \mathrm{~mm}$ ). This spectrum area is of particular interest for various reasons, as there is one order of magnitude of more spectrum available in this band than in lower bands. In addition, larger bandwidth channels can be now achieved (i.e., of $2 \mathrm{GHz}, 4 \mathrm{GHz}$, $10 \mathrm{GHz}$, or even $100 \mathrm{GHz}$ ). Massive MIMO is an extension of multiuser MIMO, in which the base station (BS) transmitter simultaneously communicates with multiple mobile station (MS) receivers using the same time-frequency resources, improving the spectrum efficiency. Massive MIMO systems can have hundreds or even thousands of antenna channels in the array. Finally, in NOMA schemes multiple users can share non-orthogonal resources in a synchronous way, thus achieving a higher spectral efficiency by allowing some degree of multiple access interference at mobile receivers [24].

It becomes apparent from the above that accurate performance evaluation and radio network planning of 5G systems can be a quite challenging and computationally demanding procedure, since a considerable number of novel technologies is introduced compared to previous wireless protocols. In general, prior to the actual deployment of a wireless cellular network, it is important to estimate a number of associated parameters, such as total capacity, maximum transmission rate both in uplink and downlink, delay, latency, outage probability, etc. Due to the large number of associated parameters (i.e., the number of active users, number of transmit/receive antennas, propagation environment, requested service per user, etc.), there are no analytical solutions for such complex wireless cellular orientations. Hence, parameter estimation can be performed only numerically, via Monte Carlo (MC) simulations [25]. Therefore, the goal of this review article is to provide all latest achievements on simulation platforms and techniques for $5 \mathrm{G}$ interfaces. In this context, channel modeling issues for massive MIMO systems and mmWave transmission are discussed, along with simulation and evaluation procedures. Additional issues, such as Radio Network Planning (RNP) and integration of high bandwidth zero latency applications (e.g., autonomous driving in future electrical smart grids, network recovery after physical disasters, or bandwidth on demand in crowded areas) are discussed as well. 
The rest of this manuscript is organized as follows: In Section 2, channel modeling issues for 5G MIMO wireless orientations are discussed, along with associated simulation procedures. In Section 3, the basic concept of system and link level simulators is described. In this context, latest achievements in 5G simulators are discussed as well. Section 4 deals with RNP issues for 5G networks, while in Section 5 additional challenging features such as Vehicle to Everything (V2X) communications in order to support bandwidth demanding applications are discussed as well. A summary of the key findings of this article in terms of simulator capabilities is provided in Section 6, while concluding remarks are provided in Section 7.

\section{Channel Modeling for MIMO Wireless Orientations}

Prior to the actual performance evaluation of a wireless cellular orientation, it is essential to have an accurate channel representation, able to represent all propagation mechanisms. With respect to Figure 1, network configuration may now vary according to traffic conditions and service demand. Therefore, the concept of fixed BS locations is no longer valid, since intermediate relay nodes can be placed throughout the 5G network topology in order to guarantee minimum Quality of Service (QoS) to MSs. In the same context, additional features, such as UAVs to support dynamic network configuration and device to device (D2D) communications impose an additional degree of complexity to the way we model channel conditions. In this framework, two main channel representations can be found in literature: Stochastic models, and deterministic ones. In the first case, these models employ ray tracing techniques in order to compute delay and other associated parameters, using geographical information [26,27]. In the second case, these parameters are calculated based on parametric models using well-known probability density functions, by means of statistical analyses of measurement data collected during extensive measurement campaigns [28]. These models are also referred as Geometry-Based Stochastic Channel Models (GSCM). The existing GSCM can be further classified into two categories: the Winner type ones and the COST ones. For the first case, various examples can be found in literature, such as the 3GPP spatial channel model (SCM), extended SCM (SCME) [29], Winner (WIM1), Winner II (WIM2) [30], Winner+ (WIM+), and QuaDRiGa [31]. Their main characteristic consists of the definition of the scatterers based on the angles of departure and angles of arrival, i.e., from a terminal perspective point of view. A typical use case is shown for example in Figure 2, where $\theta_{n, m, A o D}$, and $\theta_{n, m, A o A}$ represent the angles of departure (AoD) and arrival (AoA), respectively, for the $m^{\text {th }}$ subpath of the $n^{\text {th }}$ cluster. On the other hand, COST-type GSCM [32] defines the physical position of the scatterers in the simulation area.
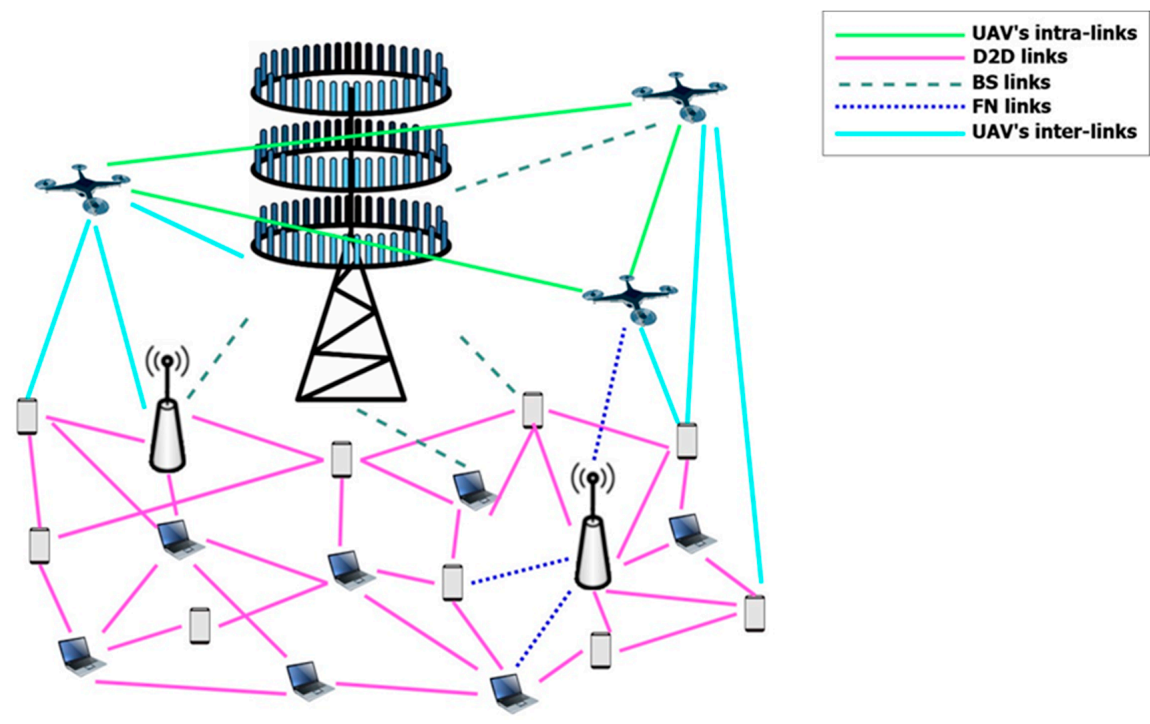

Figure 1. A fifth generation (5G) network topology with dynamic network configuration. 


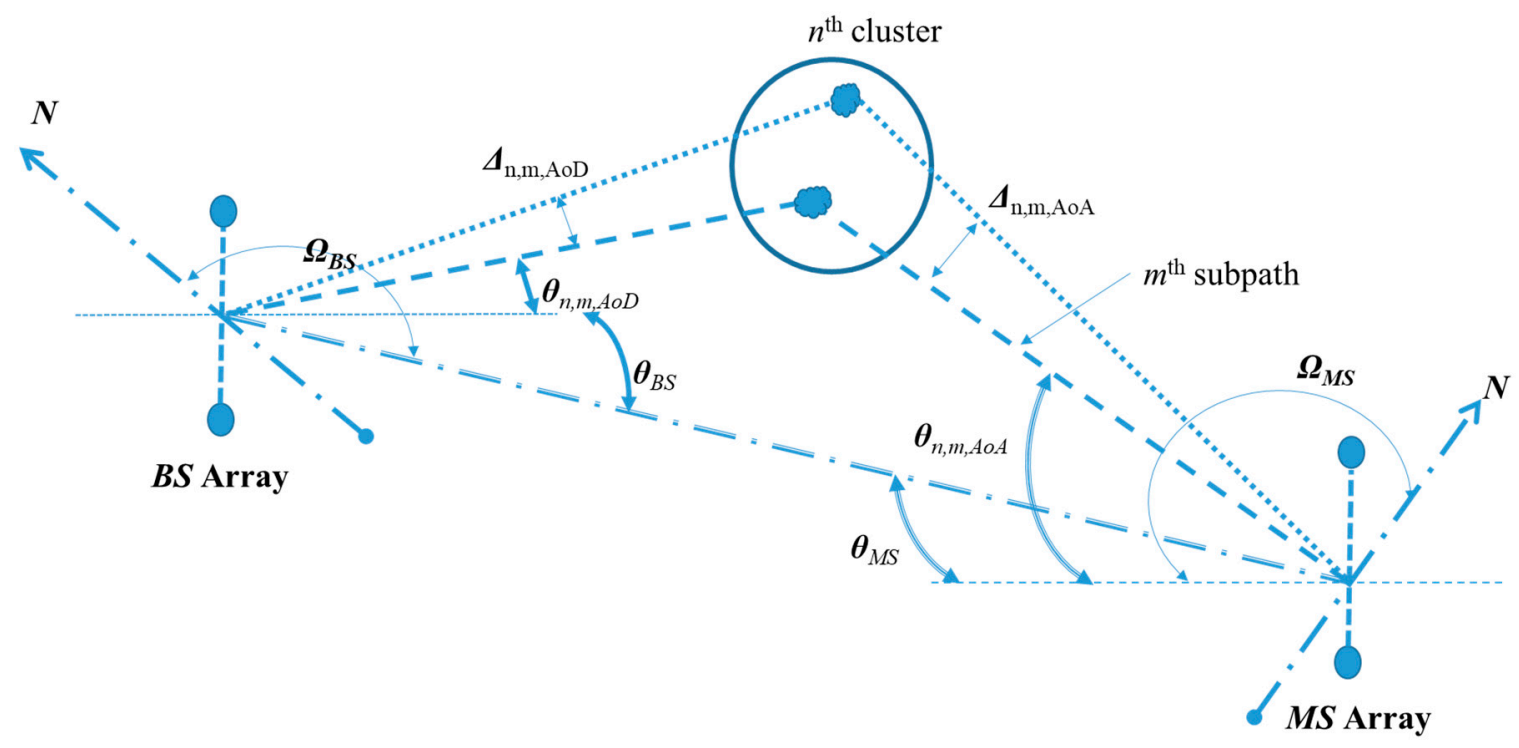

Figure 2. MIMO (multiple input multiple output) cluster channel modeling for wireless cellular networks.

A comprehensive study for all channel models proposed and evaluated in the concept of 5G networks is described in [33]. In this context, the requirements for 5G accurate channel modeling are first outlined, and then an extensive review of the recent channel measurements and models is provided. Channel measurement campaigns for MIMO orientations, vehicle-to-vehicle (V2V), high-speed train (HST) and mmWave communications are described as well. The latest 3GPP channel model (3GPP TR38.901) [34] is the extension of the widely used 3GPP 3D channel model with various additional modeling components. It supports a wide frequency range $(0.5-100 \mathrm{GHz})$ and a large bandwidth (up to $10 \%$ of carrier frequency). In 3GPP-5G modeling, a three-model representation of the MIMO channel is considered (Figure 2). In this context, the equivalent channel coefficient between an arbitrary pair of transmit/receive antenna is modeled as a set of individual channels from different clusters. In each cluster, the channel is further analyzed in a sum of $M$ subpaths. Associated parameters, such as delay spread, angular spreads, Ricean $\mathrm{K}$ factor (K), shadow fading (SF), delays of multipath components, etc., are calculated with the help of random variable generation. However, appropriate parameter selection for the random variable distribution requires extensive measurement campaigns to be conducted, with multiple technologies present, e.g., mmWave massive MIMO channel measurements [35].

With respect to Figure 3, after selecting the appropriate scenario and propagation conditions (line of sight-LOS or NLOS), the generation of final channel coefficients is based on intermediate steps computational calculations: correlated large-scale parameters, angles of arrival and departure, cross polarization ratio (XPR), cluster powers, and corresponding delays. Therefore, all aforementioned procedures can be easily implemented as separate functions during 5G network simulations. The 3GPP channel model considers spatial consistency, blockage effects, and atmosphere attenuation at mmWave. Although this is a computationally efficient approach for 5G channel modeling, the model has limited capabilities of simulating dual-mobility, antenna array non-stationarity, and spherical waves in massive MIMO. The authors in [28] propose a novel approach to extend Winner-type GSCM to include all the aforementioned issues. In particular, the studied extension proposes to share some of the clusters between users that are near to each other to achieve the desired MU consistency. The number of shared clusters is related to the distance between users, but which clusters are shared can vary according to the implementation. 


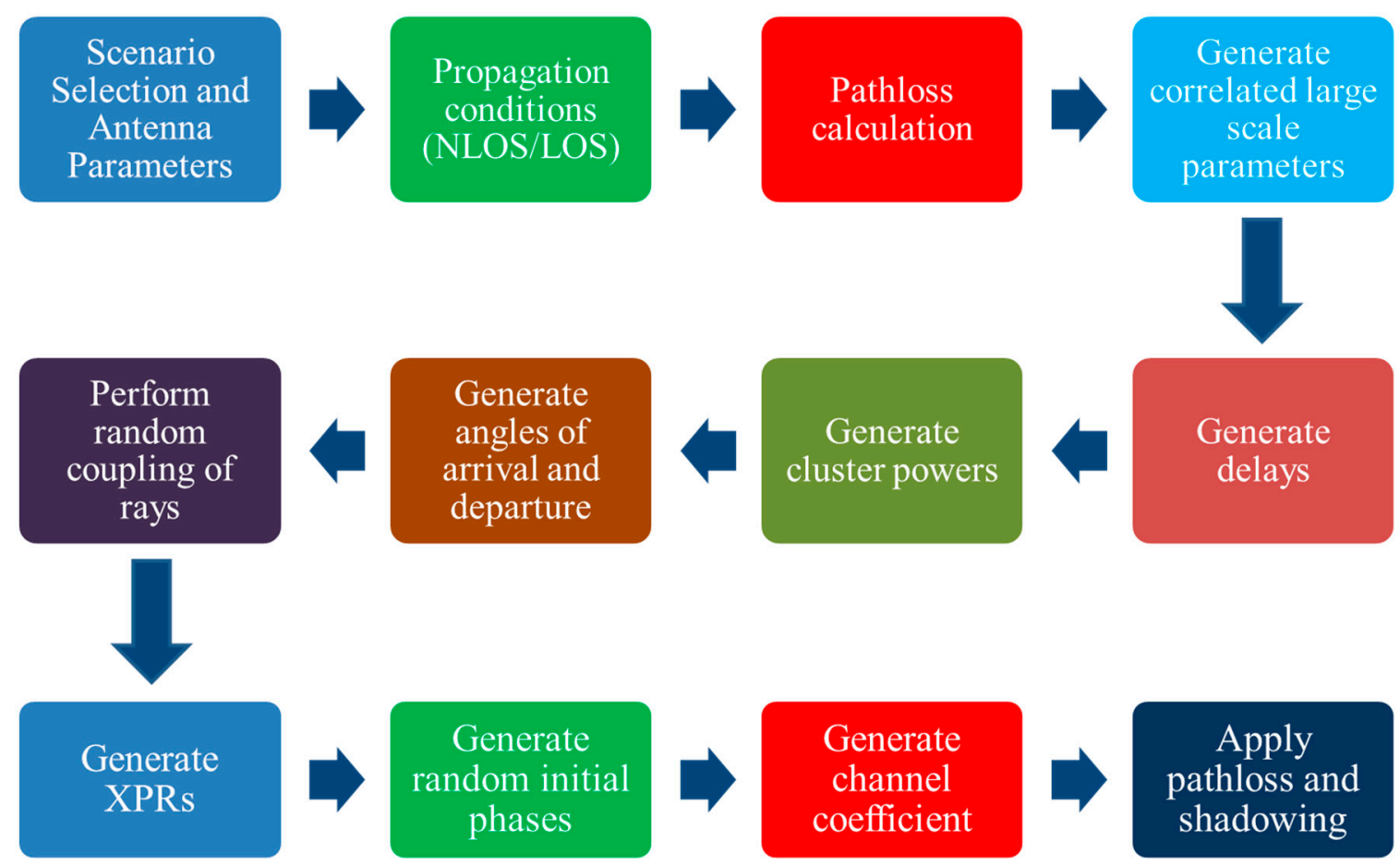

Figure 3. Channel modeling for wireless 5G cellular networks.

In the NYUSIM simulator [36], various measurements for 5G and 6G mmWave channel models have been developed from 2 to $73 \mathrm{GHz}$. In this framework, a complete statistical channel model is provided along with simulation code (in Matlab) for the generation of realistic spatial and temporal wideband channel impulse responses. These results are available for public use and suitable in 3GPP and other standard bodies and academic/industrial simulations. In this framework, in [37], an extended NYUSIM channel model with spatial consistency, human blockage and outdoor-to-indoor (O2I) penetration loss was developed. The multiple reflection surfaces method was adopted to update small-scale parameters in the spatial consistency procedure. The work in [38] presents a 3-D statistical channel impulse response (IR) model for urban LOS and non-LOS channels developed from 28- and 73-GHz ultrawideband propagation measurements in New York City. In [39], the characteristics of a spatial channel model for several mmWave bands $(28,38,60$, and $73 \mathrm{GHz})$, with the help of NYUSIM, are simulated.

Finally, additional channel configurations in the framework of 5G orientations have been studied in literature as well. In [40], the authors provide an overview of the current state of research on Device to Device (D2D) channels and discuss future trends and research directions. In [41], a simulation study is provided regarding the feasibility of public safety UAV connectivity through a 5G link at $28 \mathrm{GHz}$. As the results indicate, 5G mmWave communications can provide throughput up to 1 Gbps with consistent sub ms latency when the BS is located near the mission area, enabling remote offloading of the UAV control and perception algorithms. In [42], the authors provide a tutorial on UAV communications in 5G-and-beyond wireless networks. In this framework, new considerations, such as UAV energy limitation, high altitude, and high 3D mobility, are discussed as well. The state-of-the-art results are examined for the two main research and application paradigms of UAV communications, namely UAV-assisted terrestrial communications and cellular-connected UAVs. In [43], the statistical behavior of the path-loss from a cellular BS toward a flying UAV is modeled. The modeling principle is based on the depression angle that influences the excess in the path-loss due to two contradicting effects, the first of which is the enhanced LoS condition of the UAV and the second is the reduced BS antenna gain due to the down-tilt of the antenna pattern. 


\section{System and Link Level Simulators}

In order to simulate the behavior of a large-scale wireless cellular network, different instances of all variables involved should be considered. In this context, the concept of "drop" is defined as one simulation runs over a certain time period, during which large-scale parameters of channel remain constant, while the small-scale parameters change as a function of time. To start a new drop, users' positions are initialized again, with the channel updated at the same time [44]. Hence, the simulator can run over a large number of drops, in order to obtain statistically solid results. During each drop, a large number of packets per active user is transmitted and received, while channel parameters change according to the coherence time of the wireless orientation. Typical performance metrics include the number of active users in the network, Signal to Interference plus Noise Ratio (SINR) per user and subcarrier (in case of Orthogonal Frequency Division Multiple Access - OFDMA), BER, and outage probability. Additional parameters of particular importance, such as handover ratio, can be examined as well. After a sufficient number of MC simulations (i.e., different number of drops), the cumulative distribution function (CDF) or probability density function (pdf) of the aforementioned parameters can be extracted and evaluated for various operating scenarios. The overall procedure is depicted in Figure 4, where for simplicity only the SINR calculation is considered.

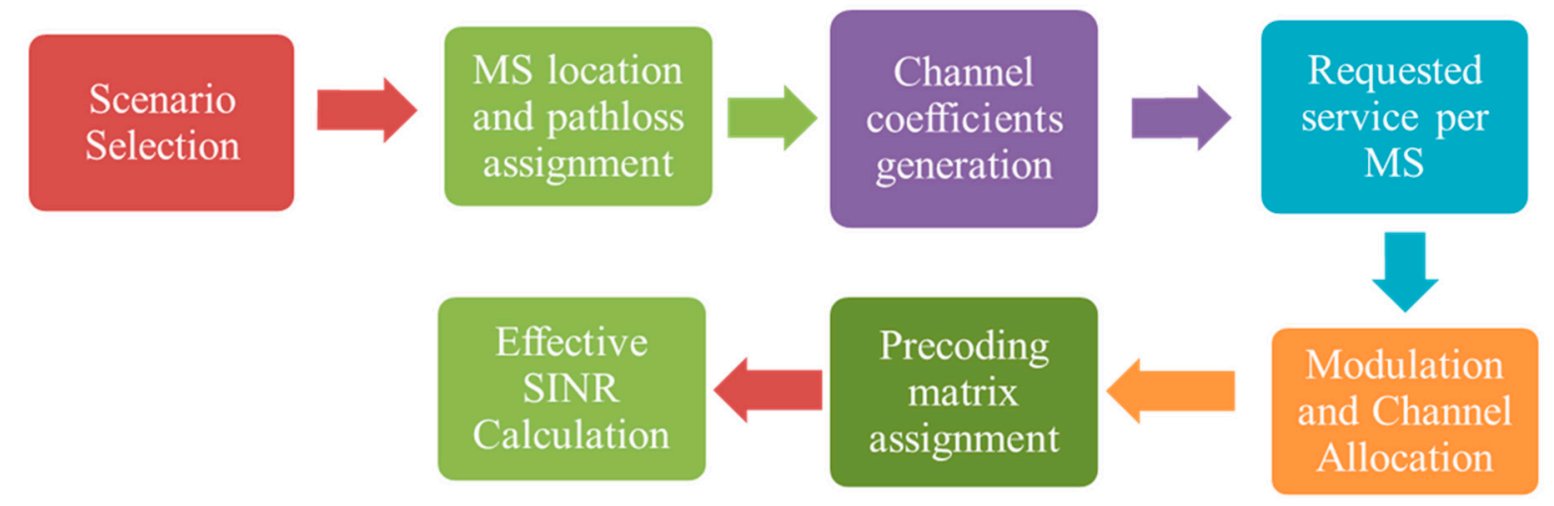

Figure 4. Cellular network simulation per channel drop.

The requested service per MS can be a simple voice call or a bandwidth demanding operation, such as the streaming of a high-definition video. Once this service has been defined, the simulator examines the appropriate modulation scheme along with channel assignment, based on predefined criteria, such as the minimization of total transmitted power, the minimum number of channels assigned, etc. In cases where full or partial Channel State Information (CSI) is available at the transmitter via an error free feedback channel, the precoding matrix assignment takes place, based on appropriate codebooks calculated a priori.

In general, the aforementioned framework can be divided into two separate procedures [45]: The first concept concerns system level (SL) simulations, which are more related to networking issues, such as resource allocation and scheduling, multi-user handling, mobility management, admission control, interference management, and network planning optimization. On the other hand, link level (LL) simulations make feasible the investigation of channel estimation, tracking, and prediction algorithms, as well as synchronization algorithms, MIMO gains, Adaptive Modulation and Coding (AMC), and feedback techniques. In a typical approach, the performance evaluation of large-scale wireless cellular networks is performed in two steps [46,47]: During the first step, limited LL simulations take place, where associated parameters are calculated for wireless orientations with a limited number of nodes. In addition, LL simulations do not define any network geometry such as cell size or user position, and therefore do not require path loss or shadow fading models. On the other hand, in SL simulations, a user's signal to noise ratio (SNR) is an input parameter to the simulation, rather than a simulation result and is directly controlled via the transmit power, path loss, and noise power level. 
In [48], an SL simulator is presented for 3G networks, where system orientation can include an increased number of cells and beams per cell. In order to reduce execution times and make feasible the simulation of scenarios with increased number of tiers and users per cell, a grid-enabled problem solving environment (PSE) has been developed (Figure 5). The framework exploits the parallelizability of MC simulations and the well-known task farming parallelization pattern. The independent MC simulations may be computed at the same time, thus reducing the simulation execution time. By using a large-scale grid-infrastructure, the parallel MC simulations may be massively executed with relatively low cost, providing solutions to time critical or exceptionally time-consuming simulations. The same platform was also used in [49], where the goal was to examine $3 \mathrm{G}$ networks for different radio resource management strategies. In both the aforementioned papers however, only system level analysis was performed.

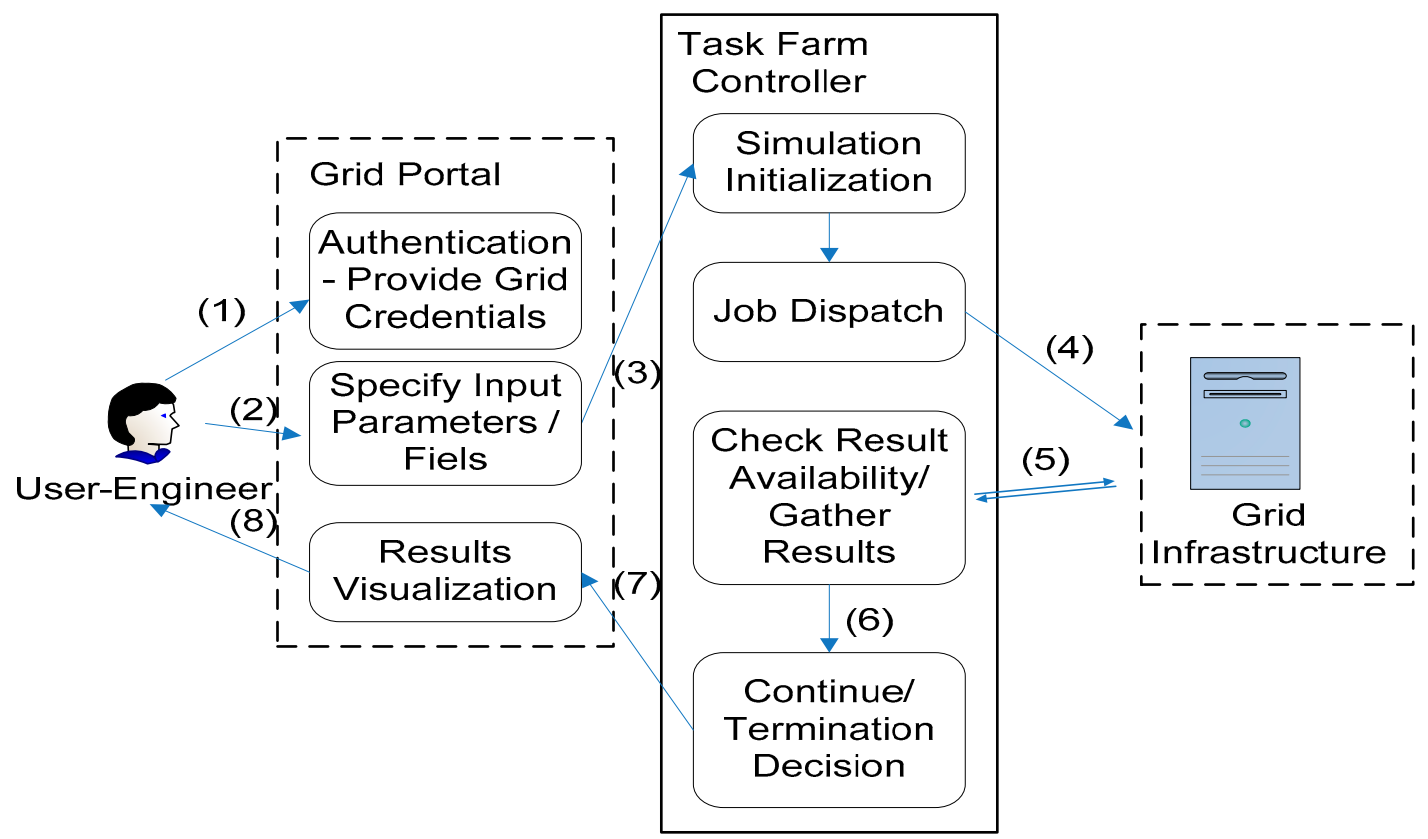

Figure 5. Grid flow for independent MC (Monte Carlo) simulations.

Moving a step forward, a hybrid system link level simulator was introduced in [50], where the performance of several precoding techniques is analyzed for MIMO-WCDMA orientations. A key advantage of the specific simulator is that now system and link level simulations are not decoupled. To tackle with the overall computational complexity, independent MC simulations were executed in parallel, using the developed framework in [48]. The concept of hybrid system-link level simulations is also followed in [51], where a 4G MIMO-OFDMA network has been considered. In [52], the open source framework LTE-Sim is presented. LTE-Sim simulates among others uplink and downlink scheduling strategies in multicell/multiuser environments, taking into account user mobility, radio resource optimization, frequency reuse techniques and the adaptive modulation and coding module. In [53], an LL simulator for the LTE downlink has been described. In this context, various parametric curves have been extracted (BER vs SINR) for several AMC schemes. These curves can be then used as input to an SL simulator. In [54], video streaming applications in LTE networks are simulated, with the help of Vienna LTE SL Simulator. The video server was integrated to the simulator, while other types of traffic were also present. In [55], a computationally efficient dynamic system-level LTE simulator for enterprise femtocell scenarios is presented. A key advantage of the specific simulator is the use of a 3D office scenario with realistic mobility and propagation models. The tool has been designed to reduce computations in real time by precomputing propagation matrices and mobility traces.

In the era of 5G, shifting Quality of Experience (QoE) towards high bandwidth and zero latency applications, the design and development of $5 \mathrm{G}$ network simulators should be able to incorporate 
among others a set of diverse technologies (i.e., mmWave channel modeling, massive MIMO, adaptive Radio Resource Management - RRM, NOMA, etc.) and support interoperability with currently established $4 \mathrm{G}$ networks. A list of all advanced features and requirements is provided in Table 1, along with a related literature review. In this context, in [56], the challenges of developing a simulation platform for 5G brought by emerging new technologies and network architectures are presented. In this framework, and in order to meet the strict requirements, a cloud-based two-level framework of an SL simulator is proposed. In [57], the Vienna LTE Simulators [58] extension to 5G networks is presented, which is a MATLAB-based LL simulation tool. In the same context, in [59], a verification of the Vienna 5G LL and SL simulators is provided. The Vienna 5G SL Simulator [60] considers wireless networks on a large scale, offering the possibility to simulate scenarios that include hundreds of nodes. In order to keep the computational complexity at a low level, link abstraction is performed; hence, link quality models (LQMs) and the link performance model (LPM) are employed. The simulation of large-scale networks with several BSs and user types and several thousand active network nodes is now possible, due to efficient implementation.

WiSE is an efficient SL simulator that has been released for the use of the industrial and academic communities. Simulation results have been validated by 3GPP calibration processes. In [61], the structure of the simulator as well as specific guidelines are presented in detail. The simulator enables LL simulations both for Orthogonal Frequency-Division Multiplexing (OFDM) and Filter Bank Multicarrier (FBMC) signals. In [62], an extension of the GTEC simulation testbed is presented ([63]), for LL simulations in 5G networks. It includes fully functional transmitter and receiver implementations, as well as different channel models and functions for processing the obtained results. In [64], a novel SL simulator framework is introduced, where remote radio head $(\mathrm{RRH})$ and the corresponding eNodeB can have a different cell ID. In [65], a new machine learning (ML) based link-to-system (L2S) mapping technique for inter-connecting an LL simulator and an SL simulator is presented and evaluated. In this context, overall computational complexity is reduced while block error rates (BLERs) prediction is improved. In [66], a new design of the SL 5G simulation platform is presented. The described simulator can support different types of networks as well as concurrent transmissions over multiple radio-access technologies for each single user, supporting either single or multiple services. In [67], a simulation analysis algorithm for 5G systems is introduced, which combines BS dormancy technology and existing power control technology, aiming at reducing BS energy consumption and improving network energy efficiency. In [68], the current status of the ns-3 framework for simulation of mmWave cellular systems is presented. The relevant implementation code, which is publicly available at GitHub [69], is highly modular and customizable to allow researchers to test novel 5G protocols. Mathworks has released the 5G Toolbox ${ }^{\mathrm{TM}}[70]$ in the framework of Matlab@, that provides standard-compliant functions and reference examples for the modeling, simulation, and verification of $5 \mathrm{G}$ communications systems. The toolbox supports LL simulations, golden reference verification and conformance testing, and test waveform generation.

The NetTest 5G Network Emulator solution [71] from Polaris Networks simulates various aspects of a 5G network. The protocol functions and interfaces of the NetTest 5G Network Emulators are implemented based on 3GPP specifications that allow users to simulate various network operations and procedures in the lab. The emulator includes, among others, a Graphical User Interface (GUI) as well as an Application Programming Interface (API) for test automation. Finally, device-oriented simulators, such as ANSYS 5G simulation solutions [72], can simulate antenna-to-antenna coupling and environmental effects on signal propagation to improve capacity and data rates for wireless applications, as well as advanced RF front-end designs and Electromagnetic Interference (EMI) mitigation techniques in 5G smartphones. 
Table 1. Main requirements for $5 \mathrm{G}$ simulators.

\begin{tabular}{|c|c|c|}
\hline Requirement & Description & $\begin{array}{c}\text { Indicative Related } \\
\text { Works }\end{array}$ \\
\hline $\begin{array}{l}\text { Network configuration should vary } \\
\text { according to traffic and channel } \\
\text { conditions }\end{array}$ & $\begin{array}{l}\text { Unlike } 3 \mathrm{G} / 4 \mathrm{G} \text { cellular systems where network configuration is } \\
\text { predefined, in the } 5 \mathrm{G} \text { network case nodes may be added } \\
\text { dynamically according to traffic conditions and overall } \\
\text { requested bit rate. }\end{array}$ & {$[41,42]$} \\
\hline $\begin{array}{l}\text { Accurate channel modeling that } \\
\text { incorporates not only BS-MS link but } \\
\text { also D2D link and intermediate relay } \\
\text { nodes. V2X communications should be } \\
\text { supported as well (Section 5) }\end{array}$ & $\begin{array}{l}\text { In order to support requested QoS, MSs with improved channel } \\
\text { gain may act as intermediate relay nodes for content caching. } \\
\text { In the physical layer, all possible channel links should be } \\
\text { embedded at the simulator }\end{array}$ & {$[26-40,68]$} \\
\hline $\begin{array}{l}\text { Adaptive RRM techniques for } 5 \mathrm{G} \\
\text { networks with dynamic configuration }\end{array}$ & $\begin{array}{l}\text { Compared to current RRM approaches, followed by traditional } \\
\text { mobile networks, 5G's RRM is quite different, since resource } \\
\text { allocation is not bounded to spatially and function-wise static } \\
\text { nodes and thus the problem, especially when trying to jointly } \\
\text { optimize a number of variables, becomes more complex. A key } \\
\text { problem is that, depending on the fronthaul capacity of different } \\
\text { links, the network might be forced to have a functional split } \\
\text { according to the current link characteristics. }\end{array}$ & {$[22,23]$} \\
\hline Heterogeneous network infrastructure & $\begin{array}{l}\text { Coexistence of } 4 \mathrm{G} / 5 \mathrm{G} \text { networks in the same geographical area, } \\
\text { as well as handover management to preserve QoS when } \\
\text { network switching takes place. }\end{array}$ & {$[60,64,66]$} \\
\hline $\begin{array}{l}\text { MU-Massive MIMO beamforming } \\
\text { techniques for data rate maximization }\end{array}$ & $\begin{array}{l}\text { Appropriate beamforming techniques are required in order to } \\
\text { support user separation and provision of acceptable QoS to all } \\
\text { MSs. Moreover, beamforming techniques should be } \\
\text { computationally efficient in order to minimize post-processing } \\
\text { complexity }\end{array}$ & {$[16,17]$} \\
\hline $\begin{array}{l}\text { Support of the increased complexity of } \\
\text { MC simulations }\end{array}$ & $\begin{array}{l}\text { 5G networks may have hundreds of nodes and increased } \\
\text { number of MSs per serving node. Hence, in order to shorten the } \\
\text { simulation time without sacrificing the simulation accuracy, } \\
\text { parallel processing using multiple cores, hardware acceleration } \\
\text { with graphic processing units, and distributed processing using } \\
\text { cloud computing should be considered. }\end{array}$ & {$[48,50]$} \\
\hline Reusability, scalability, and flexibility & $\begin{array}{l}\text { The developed code for the } 5 \mathrm{G} \text { simulators should be highly } \\
\text { reusable in various computational environments to allow } \\
\text { scientific community to test and verify all developed features. } \\
\text { High scalability and flexibility is also needed to support various } \\
\text { scenarios and technologies in a single simulator. }\end{array}$ & {$[57-59,61,68-72]$} \\
\hline
\end{tabular}

\section{Network Planning and Optimization}

Radio network planning (RNP) is an essential task for wireless networks that mainly deals with the calculation of the number, location, and configuration of the radio network nodes. Fifth generation radio planning is now of utmost importance since not only does it require cost-optimized deployments capable of handling a variety of demand constraints, but also since it then affects the optimal placement of the core network elements, e.g., for achieving low latency values. The outline of the RNP process is shown in Figure 6. The RNP optimization algorithm has various parameters as inputs, including network positioning options (dense, very dense, ultra-dense deployment), capacity and coverage requirements, as well as system constraints (total bandwidth, maximum transmission power per MS/BS). Then, optimum dimensioning takes place, where specific metrics should be satisfied, such as minimum site acquisition cost, maximum throughput in the examined area, minimum total radiated energy, or optimization of handover zones [73]. Different inputs are required to solve the cell planning difficulty, depending on the objectives in focus and the phase of planning. Usually, the following inputs need to be known: traffic models, potential site locations, BS model, and propagation prediction models. Typical outputs, include but are not limited to: the optimal number of BSs, the best locations to install BSs, the types of BS optimal for each location, the configuration of parameters, such as antenna height, number of sectors and sector orientation, tilt, power, frequency reuse pattern, as well as capacity dimensioning, e.g., number of carriers or carrier components per sector. 


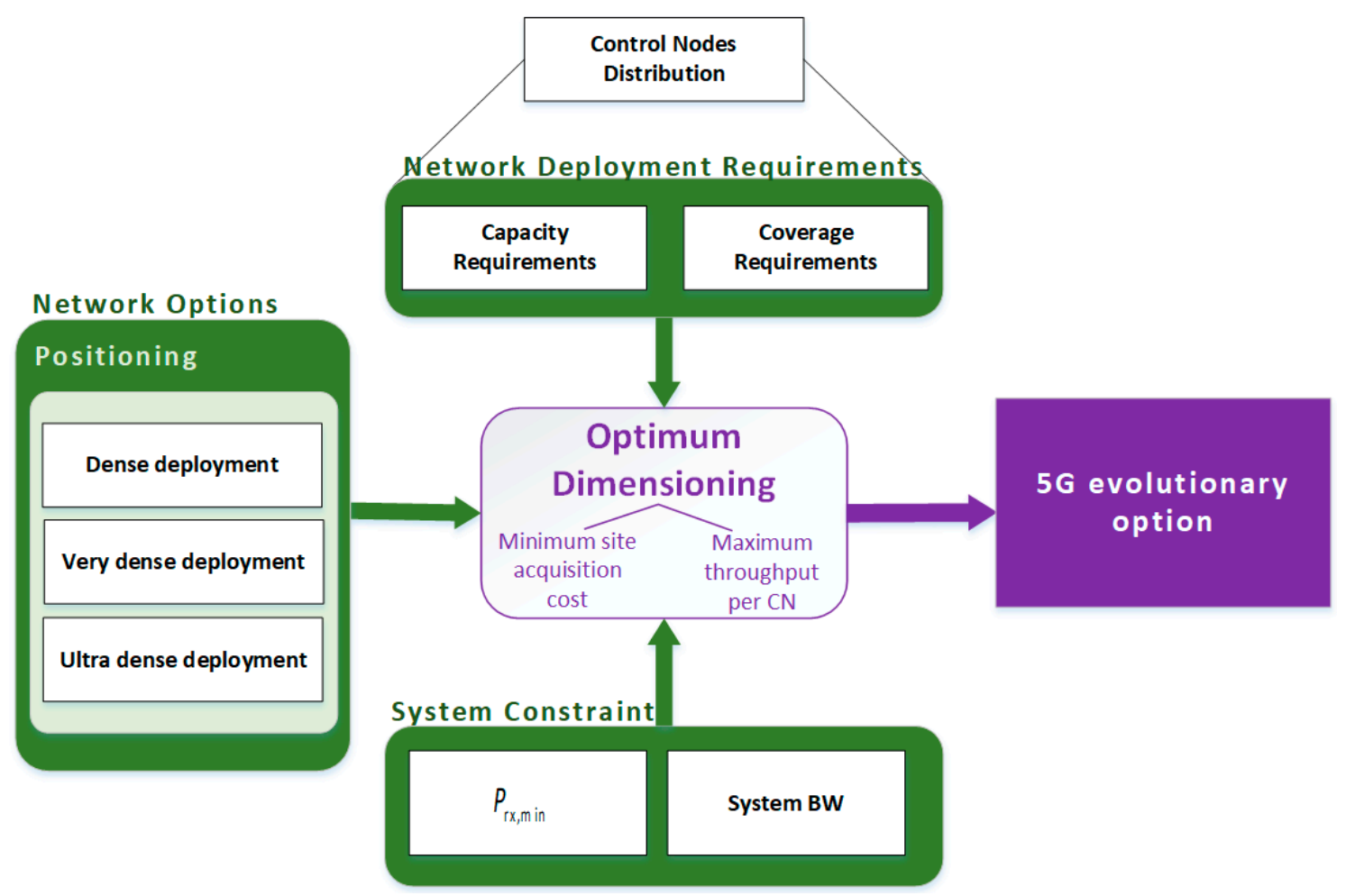

Figure 6. Radio network planning outline [74].

In this context, the work in [74] focused on providing a generic analysis for this problem, emphasizing the need for dense standalone small-cell networks in the mmWave band of $28 \mathrm{GHz}$, in order to achieve the capacity goals of 5G. The three main constraints of coverage, capacity, and cost were studied for a range of cases that reflected scenarios from dense to ultra-dense network deployments in order to achieve high capacity. In [75], a joint optimization algorithm is proposed of a multi-cell massive MIMO network towards three objectives: the power consumption, the downlink (DL) Electromagnetic (EMF) exposure, and the uplink (UL) EMF exposure. Both the DL and UL EMF exposure have been addressed in a different context. In a first step, the DL and UL EMF exposure are studied separately (E-field for the DL exposure and SAR for the UL exposure), while in a second step, the two objectives are jointly expressed in terms of the dose metric. In [76], the problem of planning a $5 \mathrm{G}$ network (and in particular BS sites) under EMF exposure limits has been studied. In this context, two real-world case-studies of currently deployed cellular networks have been examined. According to the presented results, the installation of new $5 \mathrm{G}$ sites can be quite challenging, especially in urban zones, due to the presence of the EMF saturation effect. In addition, it is shown that a sub-optimal planning, driven by strict regulations limiting the installation of new BS sites, has a not-negligible impact on the type of service that is provided by operators, as well as on the user QoS. In [77], the problem of designing emerging cellular networks like massive MIMO and LTE Narrow Band (NB)-IoT for the best possible coverage and optimal power consumption has been studied. The results indicate that massive MIMO access networks will be denser than current $4 \mathrm{G}$ technology and will offer a greater capacity. In addition, the authors have applied and introduced a novel and simple algorithm to address this issue, the Jaya-jDE algorithm. Jaya-jDE is a hybrid Jaya and differential evolution algorithm that combines concepts from both algorithms and includes a probabilistic selection mechanism and a stagnation avoidance mechanism. The proposed algorithm was compared with others in different cellular network design cases. The results indicate that in the majority of the cases it obtained a better performance than other emerging algorithms and achieved the best result in the Friedman test. In [78], the potential of full-duplex (FD) technology in enhancing the throughput and delay of 5G ultra-dense small cell networks has been investigated. The results show that the theoretical double throughput 
gain that FD promises can only be achieved under specific assumptions, namely ideal self-interference cancellation, isolated cells, and full buffer traffic model.

However, the expected gain is reduced when realistic assumptions are considered, such as traffic constraints and the inter-cell interference. In [79], a 5G architectural framework in order to address some of the $5 \mathrm{G}$ challenges is described (i.e., higher capacity, higher data rate, lower end to end latency, massive device connectivity, reduced capital and operation cost, and consistent quality of experience provisioning) and a two-layer architecture is proposed, consisting of a radio network and a network cloud. The proposed architecture integrates various enablers, such as small cells, massive MIMO, C/U-plane split, Network Function Virtualization (NFV) and Software Defined Networking(SDN). In [80], the developed RNP algorithm was oriented in order to optimize the number and locations of BSs in a given area.

Finally, many industries have also developed RNP software tools, to facilitate wireless network operators as well as academic research. In this framework, Atoll@ [81], for example, is a multi-technology wireless network design and optimization platform that supports wireless operators throughout the network lifecycle, from initial design to densification and optimization. Atoll supports mmWave propagation, massive MIMO, and 3D beamforming. In the same context, Ranplan@ [82], supports massive MIMO mmWave communications, ultra-dense and small cell heterogeneous network deployments, as well as new 5G services such as Virtual Reality (VR) and Augmented Realty (AR). Huawei has also launched appropriate simulation tools for the 5G network planning and optimization [83]. Simulation software includes network coverage for typical $5 \mathrm{G}$ services and scenarios, coverage in frequency bands including $3.5 / 4.5 / 28 / 39 \mathrm{GHz}$, the Huawei ray-tracing propagation model, as well as static beamforming and dynamic beamforming of massive MIMO.

\section{Feature Challenges}

\subsection{Integration of Autonomous Vehicles}

The era of 5G networks coincides with scientific progress in other related fields, such as the development of smart electric grids (SEGs). In this framework, bandwidth demanding and zero latency applications will be deployed and supported, such as the use of Autonomous Vehicles [84,85]. The vision for AVs is to be able to navigate without human interaction and perform additional related tasks, such as dynamic update of city maps and battery charging. As it is expected to be extremely costly for electricity companies and electric network operators to develop and set up their own wireless infrastructure to fully support the concept of EVs, a promising solution is to rent $5 \mathrm{G}$ infrastructures. Therefore, AVs will be a new type of cargo for 5G [86-88]. Smart driving poses high requirements on the transmission latency, reliability, and data rate of 5G networks. In smart driving scenarios, 5G network coverage can be affected by various factors, such as road conditions, other vehicles, and travelling speed. This describes an urgent need for more complex and refined scenario-based planning solutions.

In this context, Vehicle-to-everything (V2X) communication [89] is defined as information transmission from a vehicle to any entity that may affect the vehicle, and vice versa (Figure 7). It is a vehicular communication system that incorporates other more specific types of communication as V2I (vehicle-to-infrastructure), V2N (vehicle-to-network), V2V (vehicle-to-vehicle), V2P (vehicle-to-pedestrian), V2D (vehicle-to-device), and V2G (vehicle-to-grid). Therefore, the appropriate channel modeling of V2X channels should be incorporated in 5G network simulators as well [90]. In [91], a survey of recent developments in the area of propagation and channel modeling for vehicular communications is provided. In [92], the required steps needed for enabling V2X systems through 5G, along with the related requirements for channel modeling are discussed. In [93], the authors describe methods for deriving channel propagation models via ray-tracing simulations for mmWave transmissions with applications to V2X communications. Finally, in [94], the Internet of Vehicles (IoV) concept is described, which can be viewed as part of intelligent cities and it is characterized as an open and integrated network system, composed by several components, including vehicles, people, and things [95]. In this context, the provision 
of an IoV application (entertainment on board services delivery) has been evaluated through the ns-3 simulator, employing mmWave communications.

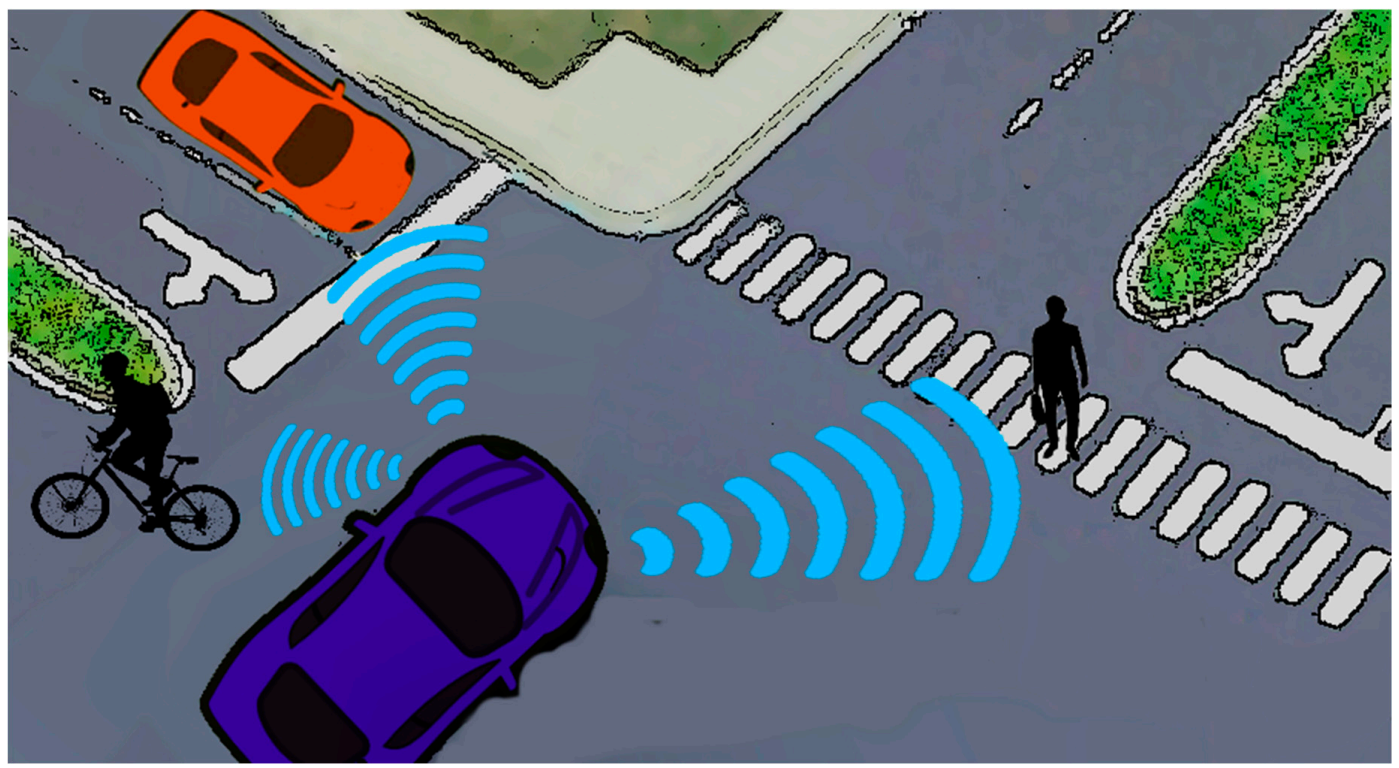

Figure 7. Autonomous vehicle in city driving.

\subsection{Beyond $5 G$}

In a 5G network, there are three categories of services whose requirements became the driving force for innovation, namely, massive machine type communications (mMTC), supporting millions of Internet of Things (IoT) devices with intermittent activity and transmissions of small data packets; ultra-reliable and low-latency communications (URLLC), allowing zero-latency communication with high reliability, such as in critical and emergency applications [96]; and enhanced mobile broadband (eMBB), accommodating traffic with high data rates, as well as cell-edge users' connectivity. Extended mMTC scenarios include hundreds of thousands of devices, automating smart city processes, such as waste disposal, asset tracking, intelligent transportation etc., demanding an Area Spectral Efficiency (ASE) exceeding $20 \mathrm{MB} / \mathrm{s} / \mathrm{m}^{2}$ that is well beyond $5 \mathrm{G}$ expectations $[97,98]$ and paves the way to its Long-Term Evolution (5G-LTE).

Taking into consideration these facts, a promising idea to design the B5G network architecture appears under the name of Ultra-Dense Networking (UDN) [99,100], implying a density of (even) thousands of nodes (drones or cars equipped with remote radio-head (RRH) or other 5G network modules) per square kilometer, while in a traditional mobile network, there are usually not more than twenty BSs in the same area. UDN is based on the deployment of static or moving, ground or flying Radio Access (RA) nodes offering improved coverage per user. More specifically, in UDNs, the transmission distance is reduced, resulting in improved link quality, while frequency reuse is maximized, increasing capacity. Under this paradigm, BSs and/or RRHs are closer to the user or are even following a user's trajectory, realizing the concept of moving access points [101]. For example, in a crowded event (Figure 8a), e.g., a music festival, a trade-fair and so on, additional connectivity is required, especially when they are hosted at less central locations where, usually, the available telco infrastructure cannot cope with the massive connectivity demands of event audiences (contrary to infrastructure-wise, well-provisioned environments like stadiums, where regular massive events are expected). A way to improve network capability for supporting such sporadic events would be the deployment of drones, positioned strategically for improved coverage and extra bandwidth to the event area, while at the same time, relaying over high-speed connections, the mobile data traffic between users and the core network. In addition, edge content caching can ease the stress on backhaul links and improve user experience. 


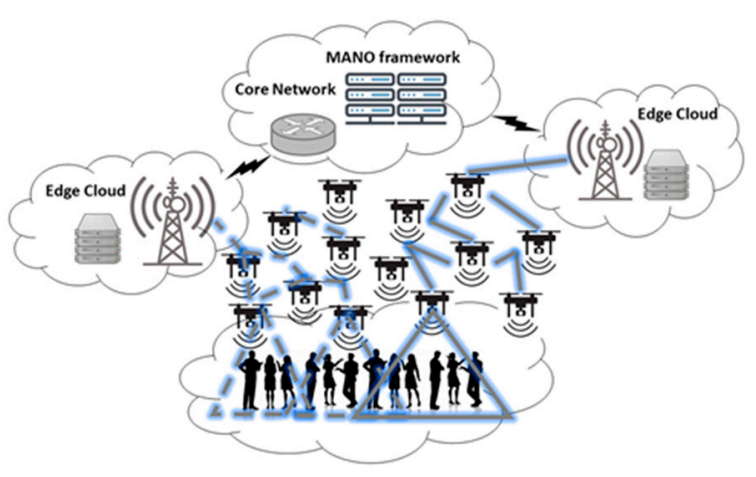

(a)

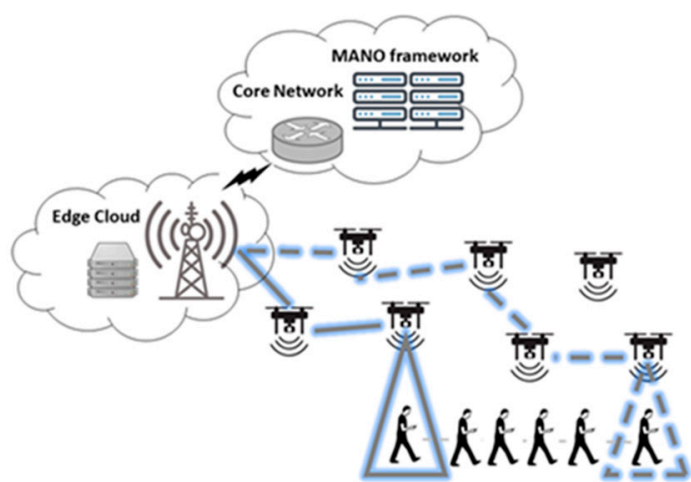

(b)

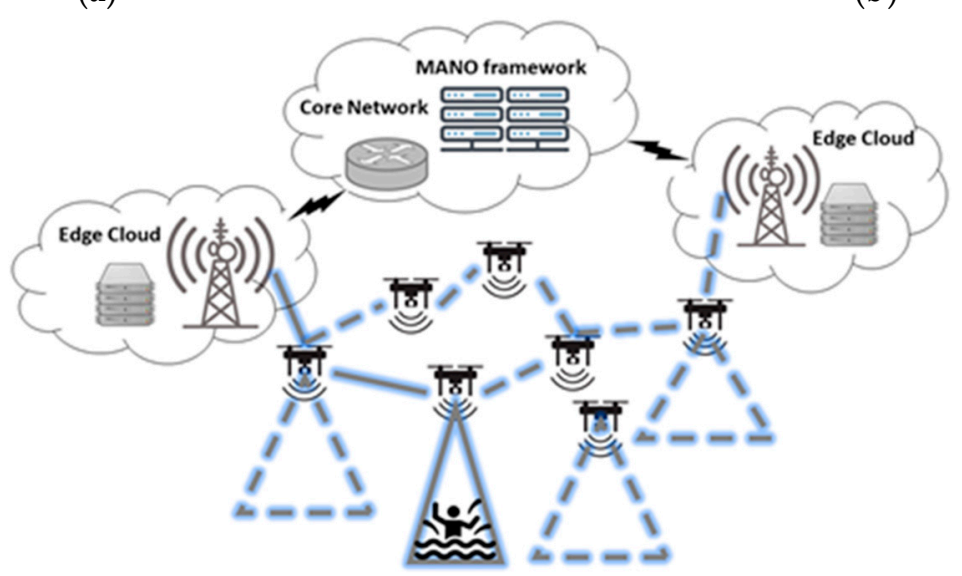

(c)

Figure 8. Fifth generation network demanding typical use case scenarios: (a) a crowded event; (b) moving users; (c) network recovery after natural disaster.

In the same context, many outdoor places of interest for groups of tourists are located slightly outside of the range of traditional telco infrastructure, including boat trips close to the coast/on a lake to see, group visits to historical sites, hiking/Segway trips to visit the local flora/fauna close to a city, etc. Connectivity can be provided to users moving around (Figure 8b), as a group, via drones, flying over the area where touristic activities are happening. The connectivity between the flying RA nodes and the core network would require some sort of medium-long-range transmission technology. A small number of drones will follow the tourists during their visits, lasting up to 80-100 minutes and cover short distances $(<=1 \mathrm{~km})$, applying flight if required by drones. Finally, after big natural disasters, such as earthquakes or hurricanes, telecom networks may have gone down, leaving both people isolated and the emergency response teams without communication capabilities via infrastructure-based cellular networks. In this case, a mobile network should be rapidly deployed (Figure 8c), focused on the disaster area, allowing the emergency response teams and the people in the area to properly communicate and access data using either internet or any other physical means, such as voice, gestures, etc. The network will follow the deployed teams, focusing on the services in the disaster area, identifying gestures and sounds coming from debris by acoustic sensors or RGB high-resolution or thermal cameras. Therefore, it becomes apparent from the above that additional challenges come to surface regarding the design and implementation of 5G networks, driven by real life applications. The existence of different services and applications with diversified characteristics leads to the simultaneous usage of network nodes, in order to give support and network for the different services, with conflicting goals on QoS and mobility for the support of the different networks. Thus, handover becomes more complicated and requires further research.

Finally, interference management is rather complex and cannot be covered by existing solutions proposed in the literature. The ultra-dense deployment of nomadic nodes, ground BSs and users/devices 
creates a complicated interference model that would be more similar to a wireless sensor network (WSN) rather than a traditional mobile communications network. Hence, system and link level simulators as well as RNP algorithms should be able to incorporate all the aforementioned bandwidth and network demanding features, for accurate performance evaluation of 5G and B5G networks.

\section{Summary}

As it became clear for the analysis of the previous sections, a complete $5 \mathrm{G}$ simulation infrastructure should be able to incorporate various aspects related to physical layer transmission (access protocols, mmWave transmission, massive MIMO, etc.), access control (adaptive RRM algorithms), dynamic network configuration with diverse elements, new bandwidth demanding services and RNP procedures. However, due to the inherent complexity of such a unified framework, simulation approaches deal with a subset of the aforementioned aspects. In the table below (Table 2), we summarize the main efforts towards 5G simulations, where the main contributions per simulation approach are highlighted.

Table 2. Summary of the most significant $5 \mathrm{G}$ simulators.

\begin{tabular}{|c|c|}
\hline Simulator & Main Characteristics \\
\hline NYUSIM & $\begin{array}{l}\text { - Statistical channel modeling, simulation code with an } \\
\text { easy-to-use interface } \\
\text { - } \quad \text { Carrier frequencies from } 2 \text { to } 73 \mathrm{GHz}\end{array}$ \\
\hline Vienna LTE Simulators & $\begin{array}{l}\text { - Simulations of 5G networks on large scale, that can include } \\
\text { hundreds of nodes Parallelization is supported } \\
\text { - } \\
\text { - }\end{array}$ \\
\hline WISE & $\begin{array}{l}\text { - } \quad \text { System level simulations of } 5 G \text { networks for multitier orientations } \\
\text { - } \quad \text { Available source code for simulations and validation }\end{array}$ \\
\hline GTEC 5G Simulator & $\begin{array}{l}\text { - } \quad \text { Link level simulations of } 5 \mathrm{G} \text { systems } \\
\text { - } \quad \text { Transceiver implementations }\end{array}$ \\
\hline$[66]$ & $\begin{array}{ll}\text { - } & \text { Heterogeneous networks } \\
\text { - } & \text { Concurrent transmissions over various access technologies } \\
\text { - } & \text { Open functional interfaces }\end{array}$ \\
\hline [68] & $\begin{array}{l}\text { - } \quad \text { mmWave transmission } \\
\text { - } \quad \text { AMC } \\
\text { - User scheduling }\end{array}$ \\
\hline 5G Toolbox by Matlab@ & $\begin{array}{ll}\text { - } & \text { Link level simulations } \\
\text { - } & \text { Channel modeling } \\
\text { - } & \text { Signal generation }\end{array}$ \\
\hline RANPLAN & $\begin{array}{ll}\text { - } & \text { Radio Network Planning } \\
\text { - } & \text { Ultra-dense small cell and heterogeneous network deployments } \\
\text { - } & \text { New 5G services such as VR/AR }\end{array}$ \\
\hline
\end{tabular}

The road towards a complete $5 \mathrm{G}$ simulator is unavoidably connected with advances in machine learning algorithms [102] in order to enable among others the system to dynamically address the ever existing problem of resources allocation, locate the fixed nodes on demand, optimize the flying path of UAV nodes, provide access to the physical and medium access control = layers through access-points auctions and handle massive cellular traffic.

\section{Conclusions}

This review article summarized all the latest achievements in simulation and evaluation techniques for emerging 5G infrastructures. In this context, several solutions have been proposed in the physical 
layer in order to support data rate requirements of 5G networks, such as mmWave transmission, massive MIMO systems, and NOMA schemes. Therefore, a complete and accurate 5G simulator should be able to incorporate all the aforementioned diverse technologies. Moreover, due to the complex nature of $5 \mathrm{G}$ networks, advanced RNP algorithms are required that can deal with dynamic network configurations (relay nodes, UAVs, etc.) according to traffic demand or other associated metrics. In this framework, various system and link level simulators were analyzed. The increased complexity of $5 \mathrm{G}$ networks indicates that a parallelization framework should be developed in order to significantly reduce execution times. However, even so, various network or application challenges impose additional degrees of complexity in the simulations. The support of autonomous vehicles and other related zero latency applications, such as dynamic network configuration with the use of UAVs, dictate the need on one hand for more accurate channel representations that are not limited to the classical BS-MS link but take into consideration additional channel orientations (e.g., D2D, V2X, relay nodes, UAV to MS, etc.) and on the other the development of advanced simulators that cover various network instances and topologies.

Author Contributions: "All authors have read and agree to the published version of the manuscript. Conceptualization, P.K.G. and D.I.K; methodology, P.K.G., P.T.T., D.I.K; formal analysis, P.K.G., P.T.T., D.I.K; investigation, P.K.G., P.T.T., D.I.K; resources, P.K.G., P.T.T., D.I.K; writing—original draft preparation, P.K.G., P.T.T., D.I.K; writing一review and editing, P.K.G., P.T.T., D.I.K.".

Funding: "This research received no external funding".

Conflicts of Interest: “The authors declare no conflict of interest".

\section{References}

1. Holma, H.; Toskala, A. (Eds.) WCDMA for UMTS. Radio Access for Third Generation Mobile Communications; Wiley: Hoboken, NJ, USA, 2004.

2. ITU-R, Report M.2134. Requirements Related to Technical Performance for IMT-Advanced Radio Interface(s), Approved in November 2008.

3. Alamouti, S. A simple transmitter diversity technique for wireless communications. IEEE J. Sel. Areas Commun. 1998, 16, 1451-1458. [CrossRef]

4. Gesbert, D.; Shafi, M.; Shiu, D.; Smith, P.; Naguib, A. From theory to practice: An overview of MIMO space-Time coded wireless systems. IEEE J. Sel. Areas Commun. 2003, 21, 281-302. [CrossRef]

5. Gesbert, D.; Akhtar, J. Breaking the barriers of Shannon's capacity: An overview of MIMO wireless systems. Telektronikk Telenor J. 2002, 1, 53-64.

6. Paulraj, A.; Gore, D.; Nabar, R.; Bolcskei, H. An overview of MIMO communications-a key to gigabit wireless. Proc. IEEE 2004, 92, 198-218. [CrossRef]

7. Shoaib, S.; Shoaib, I.; Chen, X.; Parini, C.G. MIMO antennas for next generation mobile terminals. In Proceedings of the 2016 10th European Conference on Antennas and Propagation (EuCAP), Davos, Switzerland, 10-15 April 2016; pp. 1-4.

8. Li, Q.; Li, G.J.; Lee, W.; Lee, M.; Mazzarese, D.; Clerckx, B.; Li, Z. MIMO techniques in WiMAX and LTE: A feature overview. IEEE Commun. Mag. 2010, 48, 86-92. [CrossRef]

9. Andrews, J.G.; Buzzi, S.; Choi, W.; Hanly, S.V.; Lozano, A.; Soong, A.C.K.; Zhang, J.C. What will 5G be? IEEE J. Sel. Areas Commun. 2014, 32, 1065-1082. [CrossRef]

10. Cisco, Visual Networking Index: Global Mobile Data Traffic Forecast Update 2013-2018. 2014. Available online: http://www.cisco.com/c/en/us/solutions/collateral/service-provider/visual-networking-index-vni/ white_paper_c11-520862.html (accessed on 10 March 2020).

11. Chandrasekhar, V.; Andrews, J.G.; Gatherer, A. Femtocell networks: A Survey. IEEE Commun. Mag. 2008, 46, 59-67. [CrossRef]

12. Cheng, X.; Tang, C.; Zhang, Z. Accurate channel estimation for millimeter-Wave MIMO systems. IEEE Trans. Veh. Technol. 2019, 68, 5159-5163. [CrossRef]

13. Li, L.; Wang, D.; Niu, X.; Chai, Y.; Chen, L.; He, L.; Wu, X.; Zheng, F.; Cui, T.; You, X. mmWave communications for 5G: Implementation challenges and advances. Sci. China Inf. Sci. 2018, 61, 021301. [CrossRef] 
14. Seker, C.; Güneser, M.T.; Ozturk, T. A review of millimeter wave communication for 5G. In Proceedings of the 2nd International Symposium on Multidisciplinary Studies and Innovative Technologies (ISMSIT), Ankara, Turkey, 19-21 October 2018.

15. Ji, H.; Kim, Y.; Lee, J.; Onggosanusi, E.; Nam, Y.; Zhang, J.; Lee, B.; Shim, B. Overview of full-dimension MIMO in LTE-Advanced. IEEE Commun. Mag. 2016, 55, 176-184. [CrossRef]

16. Mokhtari, Z.; Sabbaghian, M.; Dinis, R. A Survey on massive MIMO systems in presence of channel and hardware impairments. Sensors 2019, 19, 164. [CrossRef] [PubMed]

17. Larsson, E.; Edfors, O.; Tufvesson, F.; Marzetta, T. Massive MIMO for next generation wireless systems. IEEE Commun. Mag. 2014, 52, 186-195. [CrossRef]

18. Ding, Z.; Liu, Y.; Choi, J.; Sun, Q.; Elkashlan, M.; Lin, C.; Poor, H.V. Application of non-orthogonal multiple access in LTE and 5 G networks. IEEE Commun. Mag. 2017, 55, 185-191. [CrossRef]

19. Dai, L.; Wang, B.; Ding, Z.; Wang, Z.; Chen, S.; Hanzo, L. A survey of non-orthogonal multiple access for 5G. IEEE Comm. Surv. Tutor. 2018, 20, 2294-2323. [CrossRef]

20. Ding, Z.; Lei, X.; Karagiannidis, G.K.; Schober, R.; Yuan, J.; Bhargava, V.K. A survey on non-orthogonal multiple access for 5G networks: Research challenges and future trends. IEEE J. Sel. Areas Commun. 2017, 35, 2181-2195. [CrossRef]

21. Dai, L.; Wang, B.; Yuan, Y.; Han, S.; Chih-Lin, I.; Wang, Z. Non-orthogonal multiple access for 5G: Solutions, challenges, opportunities, and future research trends. IEEE Commun. Mag. 2015, 53, 74-81. [CrossRef]

22. Naqvi, S.A.R.; Hassan, S.A.; Pervaizy, H.; Ni, Q. Drone-aided communication as a key enabler for $5 \mathrm{G}$ and resilient public safety networks. IEEE Commun. Mag. 2018, 56, 36-42. [CrossRef]

23. Li, B.; Fei, Z.; Zhang, Y. UAV Communications for $5 \mathrm{G}$ and beyond: Recent advances and future trends. IEEE Internet Things J. 2019, 6, 2241-2263. [CrossRef]

24. Aldababsa, M.; Toka, M.; Gökçeli, S.; Kurt, G.K.; Kucur, O. A tutorial on non orthogonal multiple access for 5G and beyond. Hindawi Wirel. Commun. Mob. Comput. 2018, 2018, 9713450.

25. Papoulis, A.; Pillai, S. Probability, Random Variables and Stochastic Processes, 4th ed.; McGraw Hill: New York, NY, USA, 2002.

26. Jung, J.-H.; Lee, J.; Lee, J.-H.; Kim, Y.-H.; Kim, S.-C. Ray-tracing aided modeling of user-shadowing effects in indoor wireless channels. IEEE Trans. Antennas Propag. 2014, 62, 3412-3416. [CrossRef]

27. Hosain, F.; Geok, T.K.; Rahman, T.A.; Hindia, M.N.; Dimyati, K.; Ahmed, S.; Tso, C.P.; Rahman, N.Z. An efficient 3-D Ray tracing method: Prediction of indoor radio propagation at $28 \mathrm{GHz}$ in 5G Network. Electronics 2019, 8, 286. [CrossRef]

28. Mart Inez, A.M.; Egger, P.; Carvalho, E. Geometry-based stochastic channel models for5G: Extending key features for massive MIMO. In Proceedings of the 2016 IEEE 27th Annual IEEE International Symposium on Personal, Indoor and Mobile Radio Communications-(PIMRC): Fundamentals and PHY, Valencia, Spain, 4-8 September 2016.

29. Pessoa, A.M. A Stochastic channel model with dual mobility for $5 \mathrm{G}$ massive networks. IEEE Access 2019, 7, 2169-3536. [CrossRef]

30. Baum, D.S.; Hansen, J.; Galdo, G.D.; Milojevic, M. An interim channel model for beyond-3G Systems. In Proceedings of the IEEE 61st Vehicular Technology Conference, Stockholm, Sweden, 30 May-1 June 2005; pp. 3132-3136.

31. Jaeckel, S.; Raschkowski, L.; Borner, K.; Thiele, L. QuaDRiGa: A 3-D multi-cell channel model with time evolution for enabling virtual field trials. IEEE Trans. Antennas Propag. 2014, 62, 3242-3256. [CrossRef]

32. Liu, L.; Clqude, O.; Juho, P.; Katsuyuki, H.; Pertti, V.; Francois, Q.; Fredrik, T.; Philippe, D.D. The COST 2100 MIMO channel model. IEEE Wirel. Commun. 2012, 19, 92-99. [CrossRef]

33. Wang, C.-X.; Bian, J.; Sun, J.; Zhang, W.; Zhang, M. A survey of $5 \mathrm{G}$ channel measurements and models. IEEE Commun. Surv. Tutor. 2018, 20, 3142-3168. [CrossRef]

34. 3GPP TR 38.901 Version 14.3.0 Release 14. Study on Channel Model for Frequencies from 0.5 to $100 \mathrm{GHz}$. 2018.

35. Huang, J.; Wang, C.-X.; Feng, R.; Sun, J.; Zhang, W.; Yang, Y. Multi-frequency mmWave massive MIMO channel measurements and characterization for $5 \mathrm{G}$ wireless communication systems. IEEE J. Sel. Areas Commun. 2017, 35, 1591-1605. [CrossRef]

36. Available online: https://wireless.engineering.nyu.edu/nyusim/ (accessed on 10 March 2020). 
37. Ju, S.; Kanhere, O.; Xing, Y.; Rappaport, T.S. A millimeter-wave channel simulator NYUSIM with spatial consistency and human blockage. In Proceedings of the 2019 IEEE Global Communications Conference (GLOBECOM), Waikoloa, HI, USA, 9-13 December 2019; pp. 1-6.

38. Samini, M.; Rappaport, T.S. 3-D millimeter-wave statistical channel model for 5G wireless system design. IEEE Trans. Microw. Theory Technol. 2016, 64, 1-19.

39. R. Hasan, R.; Mowla, M.M.; Rashid, M.A.; Hosain, M.K.; Ahmad, I. A statistical analysis of channel modeling for 5G mmWave communications. In Proceedings of the 2019 International Conference on Electrical, Computer and Communication Engineering (ECCE), Cox's Bazar, Bangladesh, 7-9 February 2019; pp. 1-6.

40. Cheng, X.; Li, Y.; Ai, B.; Yin, X.F.; Wang, Q. Device-to-device channel measurements and models: A survey. IET Commun. 2015, 9, 312-325. [CrossRef]

41. Zeng, Y.; Wu, Q.; Zhang, R. Accessing from the sky: A tutorial on UAV communications for $5 \mathrm{G}$ and beyond. Proc. IEEE 2019, 107, 2327-2375. [CrossRef]

42. Xia, W.; Polese, M.; Mezzavilla, M.; Loianno, G.; Rangan, S.; Zorzi, M. Millimeter wave remote UAV control and communications for public safety scenarios. In Proceedings of the 16th Annual IEEE International Conference on Sensing, Communication, and Networking (SECON), Boston, MA, USA, 10-13 June 2019.

43. Al-Hourani, A.; Gomez, K. Modeling cellular-to-UAV path-loss for suburban environments. IEEE Wirel. Commun. Lett. 2018, 7, 82-85. [CrossRef]

44. 3GPP TR 25.996 v6.1.0. Spatial Channel Model for Multiple Input Multiple Output (MIMO) Simulations. September 2003.

45. Ikuno, J.C.; Wrulich, M.; Rupp, M. System level simulation of LTE networks. In Proceedings of the 2010 IEEE 71st Vehicular Technology Conference, Taipei, Taiwan, 16-19 May 2010.

46. Mehlführer, C.; Ikuno, J.C.; Šimko, M.; Schwarz, S.; Wrulich, M.; Rupp, M. The Vienna LTE simulators-Enabling reproducibility in wireless communications research. Eurasip J. Adv. Signal Process. 2011, 2011, 29. [CrossRef]

47. Wrulich, M.; Rupp, M. Computationally efficient MIMO HSDPA system-level modeling. Eurasip J. Wirel. Commun. Netw. 2009, 2009, 382501. [CrossRef]

48. Athanaileas, T.E.; Gkonis, P.K.; Athanasiadou, G.E.; Tsoulos, G.V.; Kaklamani, D.I. Implementation and evaluation of a web- based grid-enabled environment for WCDMA multibeam system simulations. IEEE Antennas Propag. Mag. 2008, 50, 195-204. [CrossRef]

49. Gkonis, P.K.; Tsoulos, G.V.; Kaklamani, D.I. Capacity of WCDMA multicellular networks under different radio resource management strategies. In Proceedings of the IEEE 3rd International Symposium on Wireless Pervasive Computing, Santorini, Greece, 7-9 May 2008.

50. Gkonis, P.K.; Tsoulos, G.V.; Kaklamani, D.I. Performance evaluation of MIMO-WCDMA cellular networks in multiuser frequency selective fading environments. Wirel. Commun. Mob. Comput. 2013, 13. [CrossRef]

51. Gkonis, P.K.; Seimeni, M.A.; Asimakis, N.P.; Kaklamani, D.I.; Venieris, I.S. A new subcarrier allocation strategy for MIMO-OFDMA multicellular networks based on cooperative interference mitigation. Sci. World J. 2014, 2014, 652968. [CrossRef] [PubMed]

52. Piro, G.; Grieco, L.A.; Boggia, G.; Capozzi, F.; Camarda, P. Simulating LTE cellular systems: An open-source framework. IEEE Trans. Veh. Technol. 2011, 60, 498-513. [CrossRef]

53. Olmos, J.; Serra, A.; Ruiz, S.; García-Lozano, M.; Gonzalez, D. Link Level Simulator for LTE Downlink. Available online: https://www.researchgate.net/publication/47330409_Link_level_simulator_for_LTE_downlink (accessed on 10 March 2020).

54. Ye, Z.; Jimenez, T.; El-Azouzi, R. Video streaming analysis in Vienna LTE system level simulator. In Proceedings of the 8th EAI International Conference on Simulation Tools and Techniques, Athens, Greece, 24-26 August 2015.

55. Ruiz-Avilés, J.M. Design of a computationally efficient dynamic system-level simulator for enterprise LTE femtocell scenarios. J. Electr. Comput. Eng. 2012, 2012, 802606. [CrossRef]

56. Wang, Y.; Xu, J.; Jiang, L. Challenges of system-level simulations and performance evaluation for 5G wireless networks. IEEE Access 2014, 2, 1553-1561. [CrossRef]

57. Pratschner, S.; Tahir, B.; Marijanovic, L.; Mussbah, M.; Kirev, K.; Nissel, R.; Schwarz, S.; Rupp, M. Versatile mobile communications simulation: The Vienna 5G link level simulator. Eurasip J. Wirel. Commun. Netw. 2018, 2018, 226. [CrossRef]

58. Institute of Telecommunications. T.U. Wien, Vienna Cellular Communications Simulators. Available online: www.tc.tuwien.ac.at/vccs/ (accessed on 10 March 2020). 
59. Pratschner, S.; Müller, M.K.; Ademaj, F.; Nabavi, A.; Tahir, B.; Tahir, B.; Schwarz, S.; Rupp, M. Verification of the Vienna 5G link and system level simulators and their interaction. In Proceedings of the 16th IEEE Annual Consumer Communications \& Networking Conference (CCNC), Las Vegas, NV, USA, 11-14 January 2019.

60. Müller, M.K.; Ademaj, F.; Dittrich, T.; Tastenbauer, A.; Elbal, B.R.; Nabavi, A.; Nagel, L.; Schwarz, S.; Rupp, M. Flexible multi-node simulation of cellular mobile communications: The Vienna $5 \mathrm{G}$ system level simulator. Eurasip J. Wirel. Commun. Netw. 2018, 2018, 227. [CrossRef]

61. Jao, C.-K.; Wang, C.Y.; Yeh, T.Y.; Tsai, C.C.; Chen, J.H.; Pao, W.C.; Sheen, W.H. WiSE: A system-level simulator for $5 \mathrm{G}$ mobile networks. IEEE Wirel. Commun. 2018, 25, 4-7. [CrossRef]

62. Tomás Domínguez-Bolaño, T.; Rodríguez-Piñeiro, J.; García-Naya, J.A.; Castedo, L. The GTEC 5G link-level simulator. In Proceedings of the 2016 1st International Workshop on Link- and System Level Simulations (IWSLS), Vienna, Austria, 1 July 2016.

63. Suárez-Casal, P.; Rodríguez-Piñeiro, J.; García-Naya, J.A.; and Castedo, L. Experimental evaluation of the WiMAX downlink physical layer in high-mobility scenarios. Eurasip J. Wirel. Commun. Netw. 2014, 2015, 109. [CrossRef]

64. Wang, X.; Chen, Y.; Mai, Z. A novel design of system level simulator for heterogeneous networks. In Proceedings of the 2017 IEEE Globecom Workshops (GC Wkshps), Singapore, 4-8 December 2017.

65. Chu, E.; Yoon, J.; Jung, B.C. A novel link-to-system mapping technique based on machine learning for 5G/IoT wireless networks. Sensors 2019, 19, 1196. [CrossRef] [PubMed]

66. Liu, M.; Ren, P.; Du, Q.; Ou, W.; Xiong, X.; Li, G. Design of system-level simulation platform for $5 \mathrm{G}$ networks. In Proceedings of the CD-ROM Proceedings of the 2017 International Conference of Electrical and Electronic Technologies for Automotive, Torino, Italy, 15-16 June 2017.

67. Yan, G. Simulation analysis of key technology optimization of 5G mobile communication network based on Internet of Things technology. Int. J. Distrib. Sens. Netw. 2019, 15. [CrossRef]

68. Mezzavilla, M.; Zhang, M.; Polese, M.; Ford, R.; Dutta, S.; Rangan, S.; Zorzi, M. End-to-End simulation of 5G mmWave networks. IEEE Commun. Surv. Tutor. 2018, 20, 2237-2263. [CrossRef]

69. NYU WIRELESS, University of Padova, ns-3 Module for Simulating Mmwave-Based Cellular Systems. Available online: https://github.com/nyuwireless-unipd/ns3-mmwave (accessed on 10 March 2020).

70. Available online: https://www.mathworks.com/products/5g.html (accessed on 10 March 2020).

71. Available online: http://www.polarisnetworks.net/5g-network-emulators.html (accessed on 10 March 2020).

72. Available online: https://www.ansys.com/solutions/technology-trends/5g (accessed on 10 March 2020).

73. Taufique, A.; Jaber, M.; Imran, A.; Dawy, Z.; Yacoub, E. Planning wireless cellular networks of future: Outlook, Challenges and Opportunities. IEEE Access 2017, 99, 1. [CrossRef]

74. Athanasiadou, G.E.; Fytampanis, P.; Zarbouti, D.A.; Tsoulos, G.V.; Gkonis, P.K.; Kaklamani, D.I. Radio network planning towards 5G mmWave standalone small-cell architectures. Electronics 2020, 9, 339. [CrossRef]

75. Matalatala, M.; Deruyck, M.; Shikhantsov, S.; Tanghe, E.; Plets, D.; Goudos, S.; Psannis, K.E.; Martens, L.; Joseph, W. Multi-objective optimization of massive MIMO 5G wireless networks towards power consumption, uplink and downlink exposure. Appl. Sci. 2019, 9, 4974. [CrossRef]

76. Chiaraviglio, L.; Cacciapuoti, A.S.; Di Martino, G.; Fiore, M.; Montesano, M.; Trucchi, D.; Melazzi, N.B. Planning 5G Networks under EMF constraints: State of the art and vision. IEEE Access 2018, 6, 51021-51037. [CrossRef]

77. Goudos, S.K.; Deruyck, M.; Plets, D.; Martens, L.; Psannis, K.E.; Sarigiannidis, P.; Joseph, W. A novel design approach for 5G massive MIMO and NB-IoT green networks using a hybrid jaya-differential evolution algorithm. IEEE Access 2019, 7, 105687-105700. [CrossRef]

78. Sarret, M.G.; Berardinelli, G.; Mahmood, N.H.; Fleischer, M.; Mogensen, P.; Heinz, H. Analyzing the potential of full duplex in 5G ultra-dense small cell networks. Eurasip J. Wirel. Commun. Netw. 2016, 2016, 284. [CrossRef]

79. Agyapong, P.K.; Iwamura, M.; Staehle, D.; Kiess, W.; Benjebbour, A. Design considerations for a 5 G network architecture. IEEE Commun. Mag. 2014, 52, 65-75. [CrossRef]

80. El-Beaino, W.; El-Hajj, A.M.; Dawy, Z. On radio network planning for next generation 5G networks: A case study. In Proceedings of the International Conference on Communications, Signal Processing, and their Applications (ICCSPA'15), Sharjah, UAE, 17-19 February 2015.

81. Available online: https://www.forsk.com/atoll-overview (accessed on 10 March 2020).

82. Available online: https://ranplanwireless.com/industries/5g/ (accessed on 10 March 2020). 
83. Huawei 5G Wireless Network Planning Solution White Paper. Available online: https://www-file.huawei.com/ -/media/corporate/pdf/white\%20paper/2018/5g_wireless_network_planing_solution_en.pdf?la=en-ch (accessed on 10 March 2020).

84. Krasniqi, X.; Hajrizi, E. Use of IoT technology to drive the automotive industry from connected to full autonomous vehicles. IFAC Pap. Online 2016, 49, 269-274. [CrossRef]

85. Skouras, T.A.; Gkonis, P.K.; Ilias, C.N.; Trakadas, P.T.; Tsampasis, E.G.; Zahariadis, T.V. Electrical vehicles: Current state of the art, future challenges, and perspectives. Clean Technol. 2020, 2, 1. [CrossRef]

86. Lema, M.A.; Laya, A.; Mahmoodi, T.; Cuevas, M.; Sachs, J.; Markendahl, J.; Dohler, M. Business case and technology analysis for $5 \mathrm{G}$ low latency applications. IEEE Access 2017, 5, 5917-5935. [CrossRef]

87. Alberio, M.; Parladori, G. Innovation in automotive: A challenge for $5 \mathrm{G}$ and beyond network. In Proceedings of the International Conference of Electrical and Electronic Technologies for Automotive, Torino, Italy, 15-16 June 2017.

88. Campolo, C.; Molinaro, A.; Iera, A.; Menichella, F. 5G Network Slicing for Vehicle-to-Everything Services. IEEE Wirel. Commun. 2017, 24, 38-45. [CrossRef]

89. Mannoni, V.; Berg, V.; Sesia, S.; Perraud, E. A comparison of the V2X communication systems: ITS-G5 and C-V2X. In Proceedings of the 2019 IEEE 89th Vehicular Technology Conference (VTC2019-Spring), Kuala Lumpur, Malaysia, 28 April-1 May 2019.

90. ETSI TR 103 257-1 V1.1.1 (2019-05), Intelligent Transport Systems (ITS), Access Layer, Part 1: Channel Models for the $5,9 \mathrm{GHz}$ frequency band. 2019.

91. Viriyasitavat, W.; Boban, M.; Tsai, H.; Vasilakos, A. Vehicular communications: Survey and challenges of channel and propagation models. IEEE Veh. Techn. Mag. 2015, 10, 55-66. [CrossRef]

92. Antonescu, B.; Moayyed, M.T.; Basagni, S. mmWave channel propagation modeling for V2X communication systems. In Proceedings of the IEEE 28th Annual International Symposium on Personal, Indoor, and Mobile Radio Communications (PIMRC), Montreal, QC, Canada, 8-13 October 2017.

93. Medbo, J.; Börner, K.; Haneda, K.; Hovinen, V.; Imai, T.; Järvelainen, J.; Jämsä, T.; Karttunen, A.; Kusume, K.; Kyröläinen, J.; et al. Channel modelling for the fifth generation mobile communications. In Proceedings of the 8th European Conference on Antennas and Propagation (EuCAP 2014), The Hague, The Netherlands, 6-11 April 2014; pp. 219-223.

94. Storck, C.R.; Duarte-Figueiredo, F. A 5G V2X ecosystem providing Internet of vehicles. Sensors 2019, $19,550$. [CrossRef]

95. Yang, F.; Wang, S.; Li, J.; Liu, Z.; Sun, Q. An overview of Internet of Vehicles. China Commun. 2014, 11, 1-15. [CrossRef]

96. 5GPPP-IA, 5G and e-Health. 2015. Available online: https://5gppp.eu/wpcontent/uploads/2016/02/5G-PPPWhite-Paperon-eHealth-Vertical-Sector.pdf (accessed on 10 March 2020).

97. IMT-2020 (5G) Promotion Group, 5G Vision and Requirement. 2014.

98. 5GPPP-IA, Smart Networks and Services for Next Generation Internet. Available online: https://5g-ppp.eu/ wp-content/uploads/2019/02/5G-IA-Position-Paper-Smart-Networks-and-Services_Horizon-Europe.pdf (accessed on 10 March 2020).

99. Al-Dulaimi, A.; Ni, Q.; Cao, J.W.; Gatherer, A.; Chih-lin, I. Orchestration of ultra-dense 5G networks. IEEE Commun. Mag. 2018, 56, 68-69. [CrossRef]

100. Kamel, M.; Walaa, H.; Amr, Y. Ultra-dense networks: A survey. IEEE Commun. Surv. Tut. 2016, 18, $2522-2545$. [CrossRef]

101. Andreev, S.; Vitaly, P.; Mischa, D.; Halim, Y. Future of ultra-dense networks beyond 5G: Harnessing heterogeneous moving cells. IEEE Commun. Mag. 2019, 57, 86-92. [CrossRef]

102. Morocho-Cayamcela, M.E.; Lee, H.; Lim, W. Machine learning for 5G/B5G mobile and wireless communications: Potential, Limitations, and Future Directions. IEEE Access 2019, 7, 137184-137206. [CrossRef]

(C) 2020 by the authors. Licensee MDPI, Basel, Switzerland. This article is an open access article distributed under the terms and conditions of the Creative Commons Attribution (CC BY) license (http://creativecommons.org/licenses/by/4.0/). 